\title{
Anxiety and depressive disorders associated with epilepsy in women of reproductive age
}

\author{
Victoria Duca \\ Department of Neurology No 1, Nicolae Testemitanu State University of Medicine and Pharmacy \\ Chisinau, the Republic of Moldova \\ Author's ORCID iD, academic degrees and contribution are available at the end of the article \\ Corresponding author: victoria.duca.a@gmail.com \\ Manuscript received August 01, 2020; revised manuscript April 12, 2021; published online April 28, 2021
}

\begin{abstract}
Background: Mental disorders in people with epilepsy are an old problem that remains crucial nowadays. The specialized literature has reported increasingly significant values of anxiety and depressive disorders associated with epilepsy in women during their child bearing age. The prevalence of depression comorbidity related to epilepsy has accounted for $55 \%$ of cases, many of which remain undiagnosed. Anxiety exceeds the frequency of depressive cases by $10-15 \%$, which tends to be milder, however showing a chronic evolution. It is important to find out the correlation between the occurrences of mental disorder in women with epilepsy from the Republic of Moldova. The purpose of the study was to assess the depressive and anxiety symptoms associated with epilepsy in women of reproductive age.

Material and methods: A retrospective cohort study was conducted on a group of 128 women with epilepsy. Patients were divided into 2 groups, with anxiety and depression respectively. Hospital and Anxiety Depression Scale (HADS) was applied for estimating anxiety and depression, being considered a priority compared to Hamilton scales, the Beck Inventory, the Zung scale.

Results: It has been proved that the disease duration and seizure recurrence are directly proportional to prevalence of depression and anxiety cases. The type of seizure remains a controversial topic.

Conclusions: Anxiety and depression in epilepsy patients show a heterogeneous nature due to clinical pleiomorphism. The HAD scale is effective for the early diagnosis of anxiety and depression in epilepsy women.

Key words: epilepsy in women, epileptic seizures, depression, anxiety.
\end{abstract}

Cite this article

Duca V. Anxiety and depressive disorders associated with epilepsy in women of reproductive age. Mold Med J. 2021;64(2):16-20. https://doi.org/10.52418/ moldovan-med-j.64-2.21.03.

\section{Introduction}

Epilepsy is a chronic neurological disorder, and the epileptic seizure (ES) is its pathognomonic sign. The disease chronicity and severity lead to mental comorbidities, particularly in women [1]. Psychiatric disorders, such as depression and anxiety, are considered more commonly encountered in women with epilepsy, thus being a challenging issue in the management of epilepsy in this population group $[2,3]$.

Anxiety is caused by subjective feelings, such as worry and physiological responses like tachycardia, hypercortisolemia, and avoidance behaviors. The characteristic signs of anxiety include a diffuse, unpleasant and vague sense of fear or anxiety, accompanied by vegetative symptoms like headaches, sweating, palpitations, tachycardia, gastric disorders, etc. It consists of two components viz. physiological and psychological ones. It might eventually affect thinking, perception and learning, thus it might potentially distort the perceptions and decrease the power of concentration, associative memory and evocation [4].

Depression is defined as a mental health disorder charac- terized by a series of symptoms resulting in a lack of positive emotional well-being, such as loss of interest and pleasure in previously rewarding or enjoyable activities and experiences, mood swings and a range of associated emotional, cognitive, physical and behavioral problems. The diagnosis of Major Depression is based on both the severity and persistence of symptoms, as well as on the level of functional and social disabilities, which refer to psychiatry $[4,5]$.

The Depression and Anxiety Screening is a mandatory for all chronic diseases, especially in epilepsy, thus becoming a medical task for neurologists and epileptologists [6].

Epidemiological data have revealed a significantly prevailing rate of depression and anxiety disorders accounting for 50-65\% of cases [7], although these indices vary depending on the research data and the development level of the country. The disease duration and severity influence the onset of these disorders. It has been proved that the prevailing $55 \%$ of depressive disorders in epilepsy is related to drugresistant epilepsy, $20-30 \%$ to recurrent seizures and even a 6-7\% incidence was found in seizure-free periods [7].

However, it should be underlined that most mental dis- 
orders remain undiagnosed [8]. On the one hand, the coexistence of depression and anxiety in epilepsy will worsen the epileptogenic brain process by deepening the brain epileptization, thus increasing the ES recurrence [8]. On the other hand, the development of mental disorders beyond depression and anxiety is likely to result in serious mental illnesses and suicide attempts $[8,9]$. Early diagnosis of mental disorders associated with epilepsy first provides possibility to identify the risk factors for the onset of these serious disorders and then optimizes antiepileptic and psychiatric treatment.

The importance of risk factors for developing depression and anxiety disorders related to epilepsy comorbidity is obvious and is under current research studies. The conclusions and recommendations of the field-related specialists are quite controversial. Some authors state that disease chronicity, drug resistance and family history are the key risk factors in developing depression and anxiety disorders, thus disregarding the significance of epileptic seizure type [10]. However, most authors suggest that the main risk factors include the ES type, particularly in focal seizures, ES recurrence, ES duration, the disease duration and hereditary tendency. This study was aimed to assess the risk factors for developing depression and anxiety in epilepsy patients and namely, type of seizure, its frequency, and disease duration.

The depressive episodes, as well as anxiety disorders including panic attacks or different types of phobias and obsessive signs, might exhibit preictal, ictal, postictal and interictal manifestations. Depression and interictal anxiety are considered the most common types of mental disorders in epilepsy [11]. However, the comparative prevalence is not known yet. The interictal period is more helpful in researching mental disorders related to epilepsy.

Therefore, comorbidity of epilepsy-related depressive disorders shows a pleomorphic nature and includes signs, such as anhedonia, irritability, dysphoria, emotional lability followed by crying spells, anxiety, no energy, pain, insomnia, frustration, difficulty of concentrating, etc.

Anxiety more commonly occurs during the interictal period, being characterized by anhedonia, anxiety, phobia, fatigue, turbulence, nervousness, muscle tension, paresthesias, etc. Anxiety and potential panic attacks are memorized by patients, particularly in focal ES, thus becoming the risk factors or triggers for epileptic seizures.

Common symptoms of anxiety and depression related to epilepsy include anhedonia, depressive mood, sense of uselessness and guilt associated with neurovegetative signs. Neurologists should be mandatorily including these signs within the epilepsy patient's screening follow-up. The psychic signs are assessed via the well-known scaled scoring described within specialized literature, such as the Hamilton scale, the Beck's Depression and Anxiety Inventory, the Zung Self-rating Depression Scale and Hospital Anxiety and Depression Scale [12].

A quantitative and qualitative informative algorithm is particularly important for accurate assessment of depression and anxiety symptoms associated with epilepsy in women, thus the Hospital Anxiety and Depression-Anxiety (HAD A) and Hospital Anxiety and Depression-Depression (HAD
- D) scales were selected for screening [13]. The HAD scale includes the common signs of these 2 mental disorders, being easily applicable since no somatic signs are necessary, as well as quite applicable and effective in conducting research studies in the Republic of Moldova.

\section{Material and methods}

The retrospective cohort analytical study was carried out in women of reproductive age (aged 15 - 49 years old) and included a sample of 128 women with epilepsy. Patients were enrolled via a primary outpatient consultation and a dynamic patient's assessment, being admitted to hospital with an increasingly recurrent ES and serial ES that show risk of developing into Status Epilepticus. The characteristics of the patients are displayed in table 1.

Table 1. General characteristics of patients

\begin{tabular}{|l|c|c|}
\hline \multicolumn{1}{|c|}{ Parameters } & $\begin{array}{c}\text { Average } \\
\text { or number }\end{array}$ & SD or $\%$ \\
\hline Age 15 - 49 years & 30.2 & 1.72 \\
\hline Education & 42.7 & 39.6 \\
\hline Higher & 45 & $35.2 \%$ \\
\hline Secondary & 76 & $59.4 \%$ \\
\hline Primary & 7 & $5.5 \%$ \\
\hline Marital status & 32 & 37.4 \\
\hline Married & 36 & $28.3 \%$ \\
\hline single/unmarried & 88 & $69.3 \%$ \\
\hline separate/divorced & 3 & $2.4 \%$ \\
\hline Widowed & 1 & $0.8 \%$ \\
\hline Occupation & 32 & 29.9 \\
\hline Employed & 74 & $57.9 \%$ \\
\hline Unemployed & 18 & $14.1 \%$ \\
\hline Students & 24 & $18.8 \%$ \\
\hline Pupils & 12 & $9.4 \%$ \\
\hline Type of ES. Total & 130 & 122.9 \\
\hline Generalized & $155 \mathrm{ES}$ & $121 \%$ \\
\hline Focal & $227 \mathrm{ES}$ & $177.3 \%$ \\
\hline not defined & $8 \mathrm{ES}$ & $6.25 \%$ \\
\hline ES incidence over the past year. Total & 1282 & 2646 \\
\hline $1 / 365$ days & $12 \mathrm{w}$ & $9.4 \%$ \\
\hline $1 / 180$ days & $11 \mathrm{w}$ & $8.6 \%$ \\
\hline $1 / 125$ days & $16 \mathrm{w}$ & $12.5 \%$ \\
\hline $1 / 90$ days & $27 \mathrm{w}$ & $21.1 \%$ \\
\hline $1 / 60$ days & $24 \mathrm{w}$ & $24 \%$ \\
\hline $1 / 30$ days & $41 \mathrm{w}$ & $32 \%$ \\
\hline $1 / 7$ days & $37 \mathrm{w}$ & $22.7 \%$ \\
\hline $1 / 1$ day & $21 \mathrm{w}$ & $16.4 \%$ \\
\hline free ES & $15 \mathrm{w}$ & $11.7 \%$ \\
\hline Disease duration (years) & 3.5 & 3.6 \\
\hline 0 years & $21 \mathrm{w}$ & $16.4 \%$ \\
\hline 1 year & $16 \mathrm{w}$ & $3.9 \%$ \\
\hline 2 years & $12.5 \%$ \\
\hline $3 y e a r s$ & $21.1 \%$ \\
\hline $5 y e a r s$ & $8.6 \%$ \\
\hline 10 years & $36.7 \%$ \\
\hline
\end{tabular}


Table 2. A and D distribution depending on ES type

\begin{tabular}{|c|c|c|c|c|c|}
\hline Item & Total & Focal ES & Generalized ES & Focal ES & Generalized ES \\
\hline Anxiety & $79 w-1.7 \%$ & $61 w-.2 \%$ & $18 w-2.7 \%$ & $19 w-32 \%$ & $22 w-3.6 \%$ \\
\hline I feel tense or wound up (points) & $170 p$ & $132 p$ & $38 p$ & & \\
\hline $\begin{array}{l}\text { I get a sort of frightened feeling as if something awful is } \\
\text { about to happen }\end{array}$ & 164 & 126 & 38 & & \\
\hline Worrying thoughts go through my mind & 171 & 129 & 42 & & \\
\hline I can't sit at ease and feel relaxed & 129 & 99 & 30 & & \\
\hline I get a sort of frightened like "butterflies" in the stomach & 120 & 96 & 24 & & \\
\hline I feel restless as if I have to be on the move & 119 & 93 & 26 & & \\
\hline I get sudden feelings of panic & 143 & 105 & 38 & & \\
\hline Total & 1016 points & 780 points & 236 points & & \\
\hline Depression & $41 w-32 \%$ & & & $19 w-32 \%$ & $22 w-53.6 \%$ \\
\hline I still enjoy the things I used to enjoy & & & & $35 p$ & $54 p$ \\
\hline I can laugh and see the funny side of things & & & & 28 & 30 \\
\hline I feel cheerful & & & & 43 & 48 \\
\hline I feel as if I am slowed down & & & & 37 & 50 \\
\hline I have lost interest in my appearance & & & & 17 & 44 \\
\hline I look forward with enjoyment to things & & & & 42 & 36 \\
\hline I can enjoy a good book or TV program & & & & 43 & 50 \\
\hline Total & & & & 245 points & 312 points \\
\hline
\end{tabular}

Table 3. Distribution of HAD-A and HAD-D test response

\begin{tabular}{|c|c|c|c|c|c|}
\hline \multirow{2}{*}{$\begin{array}{c}\text { Anxiety } \\
7 \text { groups of questions }\end{array}$} & \multicolumn{2}{|c|}{ WWFS } & \multicolumn{2}{|c|}{ WWGS } & \multirow{2}{*}{$\begin{array}{c}\text { Depression } \\
7 \text { groups of questions }\end{array}$} \\
\hline & A $61 w$ & D19w & A 18w & D & \\
\hline 0 & 0 & 5 & 0 & 0 & 0 \\
\hline 1 & 15 & 0 & 6 & 2 & 1 \\
\hline 2 & 18 & 6 & 4 & 2 & 2 \\
\hline 3 & 27 & 6 & 8 & 16 & 3 \\
\hline 0 & 3 & 1 & 0 & 0 & 0 \\
\hline 1 & 9 & 4 & 4 & 10 & 1 \\
\hline 2 & 30 & 4 & 8 & 4 & 2 \\
\hline 3 & 18 & 5 & 6 & 4 & 3 \\
\hline 0 & 6 & 0 & 0 & 0 & 0 \\
\hline 1 & 6 & 3 & 4 & 8 & 1 \\
\hline 2 & 27 & 8 & 4 & 6 & 2 \\
\hline 3 & 21 & 8 & 10 & 8 & 3 \\
\hline 0 & 0 & 2 & 2 & 2 & 0 \\
\hline 1 & 15 & 7 & 8 & 2 & 1 \\
\hline 2 & 24 & 2 & 4 & 8 & 2 \\
\hline 3 & 18 & 8 & 6 & 10 & 3 \\
\hline 0 & 15 & 2 & 6 & 2 & 0 \\
\hline 1 & 18 & 2 & 8 & 6 & 1 \\
\hline 2 & 18 & 5 & 2 & 6 & 2 \\
\hline 3 & 9 & 10 & 2 & 8 & 3 \\
\hline 0 & 9 & 2 & 2 & 2 & 0 \\
\hline 1 & 27 & 2 & 10 & 2 & 1 \\
\hline 2 & 15 & 7 & 4 & 12 & 2 \\
\hline 3 & 9 & 8 & 2 & 6 & 3 \\
\hline 0 & 9 & 0 & 2 & 0 & 0 \\
\hline 1 & 18 & 4 & 8 & 4 & 1 \\
\hline 2 & 27 & 6 & 0 & 8 & 2 \\
\hline 3 & 9 & 9 & 8 & 10 & 3 \\
\hline \multicolumn{6}{|l|}{ Total score } \\
\hline $8-10 p$ & $18 w / 29,5 \%$ & $3 w / 15.7 \%$ & $8 w / 44.4 \%$ & $4 w / 18.2 \%$ & Borderline levels A/D \\
\hline $11-14 p$ & $24 w / 39.3 \%$ & $8 w / 42.1 \%$ & $6 w / 33.3 \%$ & $10 \mathrm{w} / 45.5 \%$ & Medium levels A/D \\
\hline $15-21 p$ & $19 w / 31.1 \%$ & $8 w / 42.1 \%$ & $4 w / 22 \%$ & $8 w / 36.3 \%$ & Higher leves A/D \\
\hline
\end{tabular}

Note: WWFS - women with focal seizures, WWGS - women with generalized seizures. 
The ES diagnosis was made, based on its definition and ES diagnostic criteria settled by the International League Against Epilepsy (ILAE) [14]. The 1981 ILAE Classification of the epilepsy [15] was used in diagnosing the ES type.

According to the purpose of the research, depression and anxiety disorders were selected as factors being the most commonly associated with epilepsy, particularly in women. The assessment of depression and anxiety was based on the Hospital Anxiety and Depression Scale (HADS), which was considered sufficiently relevant. This method was designed in 1983 and includes 14 questions, 7 of which refer to A: $\mathrm{HAD}-\mathrm{A}$, and 7 are characteristic of D: HAD - D [16]. The assessment score was divided into 3 categories in both HAD - A and HAD - D scales, thus: I.> 7 - shows no A or D signs; II. 8-10 p - A / D milder form; III. 11-14 p - moderate form; IV. 15-21p - severe form. The A and D signs were separately assessed. The specialized literature shows that the sensitivity for HAD-A is $93.7 \%$ and for HAD-D is $84.6 \%$, whereas specificity makes up $72.6 \%$ for HAD-A and $90.3 \%$ for HAD-D [16].

Patients with atypical signs and severe anxiety and depressive disorders with past medical history of psychiatric monitoring were excluded from the study.

HAD was administered by a resident-neurologist and specialist-neurologist based on the patient's informed consent. Patients were informed to select responses spontaneously, based on their sensations and experiences.

The statistical analysis was performed via SPSS, the data being represented by the mean and the standard deviation values, which were applied to possible parameters.

\section{Results}

The ES, depression and anxiety characteristics were examined in 128 WWE, aged 15-49 years, the mean age was $30.2 \pm 11$ years. The study inclusion criteria were as following: all types of ES associated with depression and anxiety symptoms, except for severe and atypical forms of mental disorders. 79 (61.7\%) patients showed signs of anxiety and $41(32 \%)$ patients - depressive signs. 61 (77.2\%) patients with anxiety suffered from simple and complex focal seizures (FS) and 18 (22.7\%) - primary and secondary generalized seizures (GS), showing predominantly significant values compared to patients with depression. Signs of depression were found in 41 patients, whereas 19 patients (32\%) exhibited FS and 22 (53.6\%) - GS. Depending on the severity of the mental disorders, women with FS showed a more pronounced anxiety and made up 39.3\% of medium severe cases (HAD-A scored 11-14p) and $31.1 \%$ of severe cases (HAD-A score 15-21p) compared to women with GS. The group of GS patients showed anxiety disorders in $33.3 \%$ of moderate to severe cases and in $22.1 \%$ of severe cases, depending on the HAD-A score.

The higher incidence of depressive symptoms was recorded in GS women $-53.6 \%$ of cases vs FS - 32\% of patients. Moreover, depending on the disease severity, moderate-to-severe signs of depression were recorded via HAD-D score of 11-14 that were slightly more pronounced in GS cases, and accounted for $45.5 \%$ vs. $42.1 \%$ of FS cases, respec- tively. However, signs of severe depression were determined in the group of patients with FS $-42.15 \%$ vs $36.3 \%$ in women with GS. The anxiety and depression signs, as well as the quantified response were distributed according to the type of epileptic seizure that is shown in tables 2 and 3 .

The obtained study results of the correlation between the frequency of epileptic seizures with anxiety and depression, revealed a directly proportional relation between these parameters in $93.7 \%$ of cases. Thus, the HAD-A and HAD-D score showed high levels of 15-21 in recurrent ES cases, ranging from $1 \mathrm{ES} /$ day, $1 \mathrm{ES} /$ week to $1 \mathrm{ES} / \mathrm{month}$, in both types of mental disorders. The recurrent ES cases ranging from 1ES / month and 1ES/year, the HADS score had a mean value of 11-14 p. respectively, without revealing any prevalence in 41 patients with depression or 79 patients suffering from anxiety. The 8-10 HADS score registered patients with 1 / year or less than 1 / year ES recurrence, as well as seizure-free patients for over 1 year.

The disease duration over 5 years, as well as over 10 years determined an increasing tendency of depression signs with $15-21$ HAD-D score in $65 \%$ vs anxiety HAD-A in $53 \%$ of cases. Anxiety was determined in $57 \%$ of cases, predominantly found in the group of patients with 0-2 years of disease duration with a score of 15-21 HAD-A vs depression - found in $18 \%$ of cases.

\section{Discussion}

The results of this study showed a significant correlation between epilepsy in women and anxiety and depression that was determined in the dynamics of epileptic disease. The HADS scaled score proved to be sufficiently relevant to assess the prevalence of anxiety and depression disorders, depending on the type and recurrence of seizures, as well as on the disease duration. The research results confirmed that the disease chronicity has a greater impact on depression vs anxiety, being a major risk factor for developing mental disorders in epilepsy [17]. This study revealed about $90 \%$ incidence rate of anxiety and depression in the group of women of reproductive age, suffering from epilepsy for over 1 to 10 years. However, some depression and anxiety disorders were likely to be caused by several endogenous and constitutive factors, such as hereditary tendency, antiepileptic medication, non-diagnosed early mental symptoms, etc.

As regarding the ES type, it has been proven that it had a less impact on the development of mental disorders compared to the ES recurrence and disease duration. However, focal ES has been mostly associated with anxiety, whereas generalized ES referred to different types of depressive disorders.

Women with high depression and anxiety severity levels established via HADS score are recommended to be further checked by psychiatrist and undergo a more complex psychometric scale assessment in order to prevent serious mental disorders and initiate an early psychiatric treatment [18].

\section{Conclusions}

The analysis of the depression and anxiety symptoms associated with epilepsy in women of reproductive age revealed the following: 
1. Depression and anxiety comorbidity in epilepsy exhibit a heterogeneous nature, determined by the polymorphism of the clinical signs.

2. The HADS scale was sufficiently relevant for screening anxiety and depression disorders associated with epilepsy in women aged 15-49 years.

3. The disease duration and the recurrent epileptic seizures are major risk factors for developing depression and anxiety in epilepsy women.

4. Correlation between anxiety and depression and the ES type is quite controversial, thus requiring further studies by using instrumental investigations, such as global neuroimaging and electroencephalography studies, as well as the analysis of antiepileptic drug therapy.

5. The anxiety and depression disorders in women with epilepsy might be potentially diagnosed earlier if applying the screening HADS scale assessment in primary and dynamic neurological examination of all patients with epilepsy, in order to identify early signs of mental disorders, prevent suicide attempts, improve the quality of life and manage proper treatment.

\section{References}

1. Ekinci O, Titus JB, Rodopman AA, Berkem M, Trevathan E. Depression and anxiety in children and adolescents with epilepsy: prevalence, risk factors, and treatment. Epilepsy Behav. 2009 Jan;14(1):8-18. doi: 10.1016/j.yebeh.2008.08.015.

2. Kanner AM. Depression and epilepsy: a new perspective on two closely related disorders. Epilepsy Curr. 2006;6(5):141-6. doi: 10.1111/j.15357511.2006.00125.x.

3. Jackson MJ, Turkington D. Depression and anxiety in epilepsy. J Neurol Neurosurg Psychiatry. 2005;76 (Suppl 1):i45-i47. doi: 10.1136/ jnnp.2004.060467.

4. Lambert MV, Robertson MM. Depression in epilepsy: etiology, phenomenology, and treatment. Epilepsia. 1999;40 Suppl 10:S21-47. doi:10.1111/j.1528-1157.1999.tb00884.x.

5. Mursa I, Cobîleanschi O, Prospât T, Popov A. Abordarea pluridimensională a urgențelor psihiatrice în epilepsie [The multi-dimensional approach of psychiatric emergencies in epilepsy]. Sănătate Publică, Economie și Management în Medicină [Public Health Econ Manag Med] (Chisinau). 2016;(5/69):44-49. Romanian.

6. Soares-Filho GL, Freire RC, Biancha K, Pacheco T, Volschan A, Valença AM, Nardi AE. Use of the hospital anxiety and depression scale (HADS) in a cardiac emergency room: chest pain unit. Clinics (Sao Paulo). 2009;64(3):209-14. doi: 10.1590/s1807-59322009000300011.
7. Plevin D, Smith N. Assessment and management of depression and anxiety in children and adolescents with epilepsy. Behav Neurol. 2019 May 2;2019:2571368. doi: 10.1155/2019/2571368.

8. Baxendale SA, Thompson PJ, Duncan JS. Epilepsy \& depression: the effects of comorbidity on hippocampal volume - a pilot study. Seizure. 2005;14(6):435-8. doi: 10.1016/j.seizure.2005.07.003.

9. Tăbîrță V, Cobîleanschi O, Babin C. Aspecte medico-legale în epilepsie şi incidența stărilor crepusculare în săvârşirea acțiunilor socialmente periculoase [Forensic aspects in epilepsy and the incidence of twilight states in committing socially dangerous actions]. In: [Scientific Annals of Nicolae Testemitanu State University of Medicine and Pharmacy. 13th ed. Vol. 3]. Chisinau: Medicina; 2012. p. 427-430. Romanian.

10. Hughes J, Devinsky O, Feldmann E, Bromfield E. Premonitory symptoms in epilepsy. Seizure. 1993 Sep;2(3):201-3. doi: 10.1016/s10591311(05)80128-1.

11. Blanchet P, Frommer GP. Mood change preceding epileptic seizures. J Nerv Ment Dis. 1986 Aug;174(8):471-6. doi: 10.1097/00005053198608000-00005.

12. Bocerean C, Dupret E. A validation study of the Hospital Anxiety and Depression Scale (HADS) in a large sample of French employees. BMC Psychiatry. 2014;14:354. doi: 10.1186/s12888-014-0354-0.

13. Rishi P, Rishi E, Maitray A, Agarwal A, Nair S, Gopalakrishnan S. Hospital anxiety and depression scale assessment of 100 patients before and after using low vision care: a prospective study in a tertiary eye-care setting. Indian J Ophthalmol. 2017 Nov;65(11):1203-1208. doi: 10.4103/ ijo.IJO_436_17.

14. Fisher RS, Acevedo C, Arzimanoglou A, Bogacz A, Cross JH, Elger CE, Engel J Jr, Forsgren L, French JA, Glynn M, Hesdorffer DC, Lee BI, Mathern GW, Moshe SL, Perucca E, Scheffer IE, Tomson T, Watanabe M, Wiebe S. ILAE official report: a practical clinical definition of epilepsy. Epilepsia. 2014 Apr;55(4):475-82. doi: 10.1111/epi.12550.

15. Gao H, Sander JW, Xiao Y, Zhang Y, Zhou D. A comparison between the 1981 and 2017 International League Against Epilepsy classification of seizure types based on an outpatient setting. Epileptic Disord. 2018;20(4):257-264. doi: 10.1684/epd.2018.0982.

16. Botega NJ, Bio MR, Zomignani MA, Garcia C Jr, Pereira WA. [Mood disorders among inpatients in ambulatory and validation of the anxiety and depression scale HAD]. Rev Saude Publica. 1995 Oct;29(5):355-63. doi: 10.1590/s0034-89101995000500004. Portuguese.

17. Alexopoulos G, Kasper S, Möller HJ, Moreno C. Ghidul scalelor de evaluare a tulburării depresive majore [Guide to major depressive disorder assessment scales]. Targu-Mureș: Farmamedia; 2015. 102 p. ISBN: 978- 606-8215-49-5. Romanian.

18. Popov A. Algoritmul retragerii tratamentului de întreținere pentru pacienții cu tulburări psihice și de comportament în epilepsie [Algorithm of withdrawal of maintenance treatment for patients with mental and behavioral disorders in epilepsy]. In: [National scientific conference with international participation "Integration through research and innovation"; 2019 Nov 17-19; Chisinau, Republic of Moldova]. Chisinau: USM; 2019. p. 186-190. Romanian.

\section{Author's ORCID iD and academic degrees}

Victoria Duca, MD, PhD Applicant - https://orcid.org/0000-0003-2147-9359

\section{Author's contribution}

VD conceptualized the idea, conducted literature review, collected the data, interpreted the data, and wrote the manuscript.

\section{Funding}

This study was supported by Nicolae Testemitanu State University of Medicine and Pharmacy. The trial was the author's initiative. The author is independent and takes responsibility for the integrity of the data and accuracy of the data analysis.

\section{Ethics approval and consent to participate}

The study was approved by the Research Ethics Committee of Nicolae Testemitanu State University of Medicine and Pharmacy (Report No 71 of 17.06. 2016). An informed consent from all participants in the study was obtained.

\section{Conflict of Interests.}

There is no known conflict of interests to declare. 